\title{
Fixed point results of Edelstein-Suzuki type multivalued mappings on b-metric spaces with applications
}

\author{
Hanan Abdulaziz Alolaiyan ${ }^{\mathrm{a}, *}$, Basit Alib, Mujahid Abbas ${ }^{\mathrm{c}, \mathrm{d}}$ \\ a Mathematical Department, King Saud University, Saudi Arabia. \\ ${ }^{b}$ Department of Mathematics and Applied Mathematics, University of Pretoria, Lynnwood road, Pretoria 0002, South Africa. \\ ${ }^{c}$ Department of Mathematics University of Management and Technology, C-II, Johar Town, Lahore Pakistan. \\ ${ }^{d}$ Department of Mathematics, King Abdulaziz University, P. O. Box 80203, Jeddah 21589, Saudi Arabia.
}

Communicated by C. Vetro

\begin{abstract}
We obtain Edelstein-Suzuki type theorems for multivalued mappings in compact b-metric spaces. Moreover, we prove the existence of coincidence and common fixed points of a hybrid pair of mappings that satisfies Edelstein-Suzuki type contractive condition. We present some examples along with a comparison with results in existing literature. In the end, we present some corollaries in the metric spaces with applications in best approximation theory. (c)2017 All rights reserved.
\end{abstract}

Keywords: Edelstein-Suzuki, metric space, multivalued mapping, best approximations, fixed point. 2010 MSC: 47H10, MSC 47H04, 47H07.

\section{Introduction}

Let $(X, d)$ be a metric space and $C B(X)$ a collection of nonempty closed and bounded subsets of $X$. The Hausdorff metric $\mathrm{H}$ on $\mathrm{CB}(\mathrm{X})$ induced by the metric $\mathrm{d}$ on $\mathrm{X}$ is defined as follows:

$$
H(A, B)=\max \left\{\sup _{x \in A} d(x, B), \sup _{y \in B} d(y, A)\right\},
$$

for all $A, B \in C B(X)$, where $d(x, B)=\inf _{y \in B} d(x, y)$.

It is well-known that $(\mathrm{CB}(\mathrm{X}), \mathrm{H})$ is a complete metric space, if $(X, \mathrm{~d})$ is complete metric space.

The collection of nonempty closed subsets of $X$ is denoted by $\mathrm{Cl}(X)$.

A self-mapping $f$ on $X$ is called contraction, if there exists a real number $r$ in $[0,1)$ such that

$$
d(f x, f y) \leqslant r d(x, y)
$$

\footnotetext{
*Corresponding author

Email addresses: holayan@ksu.edu.sa (Hanan Abdulaziz Alolaiyan), basit.aa@gmail.com (Basit Ali), abbas.mujahid@gmail.com (Mujahid Abbas)

doi:10.22436/jnsa.010.03.28
} 
for all $x, y \in X$. One of the basic and the most widely applied result in metric fixed point theory is "Banach (or Banach- Caccioppoli) contraction principle" due to Banach [3]. It states that if $(X, d)$ is a complete metric space and $f: X \rightarrow X$ a contraction mapping, then $f$ has a unique fixed point.

To establish the existence and uniqueness of solution of an operator equation $f(x)=x$, particularly to prove the existence of solution of differential or integral equations, Banach contraction principle guarantees the convergence of a sequence of successive approximations of a required solution. Due to its applications in mathematics and other related disciplines, this principle has been generalized in many directions (see $[6,8,12,16,27,28]$ ).

A self-mapping $f$ on $X$ is called strictly contraction, if

$$
d(f x, f y)<d(x, y),
$$

for all $x, y \in X$ with $x \neq y$. A strictly contraction mapping defined on a complete metric space $X$ need not to have a fixed point. However, if strictly contraction mapping has a fixed point, then it is always unique.

To prove the existence of a fixed point of strictly contraction mapping, Edelstein [12] imposed a restriction on the domain of a mapping and proved the following result.

Theorem 1.1 ([12]). Let $(\mathrm{X}, \mathrm{d})$ be a compact metric space and $\mathrm{f}: \mathrm{X} \longrightarrow \mathrm{X}$ a strictly contraction mapping. Then $\mathrm{f}$ has a unique fixed point.

Suzuki [27] presented an interesting extension of a contraction mapping and employed it to characterize the completeness of domain of such mapping. This result is remarkable in the sense that existence of a fixed point of contraction mapping does not characterize the completeness of domain of contraction mapping [25].

Suzuki [27] proved a variant of Edelstein result as follows.

Theorem 1.2. Let $(X, d)$ be a compact metric space and $f: X \rightarrow X$. If for any $x, y \in X$ with $\frac{1}{2} d(x, f x)<d(x, y)$ implies that $\mathrm{d}(\mathrm{fx}, \mathrm{fy})<\mathrm{d}(\mathrm{x}, \mathrm{y})$, then $\mathrm{f}$ has a unique fixed point.

Recently, Doric et al. [11] generalized above theorem as follows.

Theorem 1.3 ([11]). Let $(X, d)$ be a compact metric space and $\mathrm{f}: \mathrm{X} \longrightarrow \mathrm{X}$. If for any $\mathrm{x}, \mathrm{y} \in \mathrm{X}$

$$
\frac{1}{2} d(x, f x)<d(x, y)
$$

implies that

$$
d(f x, f y)<A d(x, y)+B d(x, f x)+C d(y, f y)+D d(x, f y)+E d(y, f x),
$$

where $\mathrm{A}, \mathrm{B}, \mathrm{C}, \mathrm{D}, \mathrm{E} \geqslant 0, \mathrm{~A}+\mathrm{B}+\mathrm{C}+2 \mathrm{D}=1$ and $\mathrm{C} \neq 1$, then $\mathrm{f}$ has a fixed point. Moreover, $\mathrm{f}$ has a unique fixed point, if $\mathrm{E} \leqslant \mathrm{B}+\mathrm{C}+\mathrm{D}$.

Popescu [21] proved the following generalization of Theorem 1.2.

Theorem 1.4 ([21]). Let $(X, d)$ be a compact metric space and $f: X \longrightarrow X$. If for any $x, y \in X, \operatorname{ad}(x, f x)+$ $\mathrm{bd}(\mathrm{y}, \mathrm{fx})<\mathrm{d}(\mathrm{y}, \mathrm{x})$ implies that $\mathrm{d}(\mathrm{fx}, \mathrm{fy})<\mathrm{d}(\mathrm{x}, \mathrm{y})$, where $\mathrm{a}, \mathrm{b}>0$ and $2 \mathrm{a}+\mathrm{b}<1$, then $\mathrm{f}$ has a unique fixed point.

Karapinar [17, 18] obtained the following Edelstein-Suzuki type theorem.

Theorem 1.5 ([17]). Let $(X, d)$ be a compact metric space and $f: X \longrightarrow X$. If for any $x, y \in X$,

$$
\frac{1}{2} d(x, f x)<d(x, y)
$$

implies that

$$
d(f x, f y)<\max \left\{d(x, y), d(x, f x), d(y, f y), \frac{d(x, f y)}{2}, \frac{d(y, f x)}{2}\right\},
$$

then $\mathrm{f}$ has a unique fixed point. 
Nadler [20] proved the multivalued version of a Banach contraction principle as follows.

Theorem 1.6 ([20]). Let $(\mathrm{X}, \mathrm{d})$ be a complete metric space. If a multivalued mapping $\mathrm{T}: \mathrm{X} \longrightarrow \mathrm{CB}(\mathrm{X})$ satisfies

$$
H(T x, T y) \leqslant k d(x, y),
$$

for all $x, y \in X$ and for some $k \in[0,1)$, then $F(T)=\{x \in X: x \in T x\}$ is nonempty.

Shaddad et al. [22] obtained the following result:

Theorem 1.7 ([22]). Let $(X, d)$ be a compact metric space and $\mathrm{T}: \mathrm{X} \longrightarrow \mathrm{Cl}(\mathrm{X})$. If for any $\mathrm{X}, \mathrm{y} \in \mathrm{X}$, there exists some $\mathrm{r} \in\left[0, \frac{1}{2}\right)$ such that $\frac{1}{2} \mathrm{~d}(\mathrm{x}, \mathrm{T} \mathrm{x})<\mathrm{d}(\mathrm{x}, \mathrm{y})$ implies that

$$
H(T x, T y)<r \max \left\{d(x, y), d(x, T x), d(y, T y), \frac{d(x, T y)+d(y, T x)}{2}\right\}
$$

then $\mathrm{F}(\mathrm{T})$ is nonempty.

Due to the contractive constant $r \in\left[0, \frac{1}{2}\right)$, above theorem is not an exact multivalued version of Theorem 1.2.

Beg and Aleomraninejad [4] proved the following result in this direction.

Theorem $1.8([4])$. Let $(\mathrm{X}, \mathrm{d})$ be a compact metric space and $\mathrm{T}: \mathrm{X} \longrightarrow \mathrm{CB}(\mathrm{X})$. If for any $\mathrm{x}, \mathrm{y} \in \mathrm{X}$, there exists some $\mathrm{r} \in\left(0, \frac{1}{2}\right]$ such that $\mathrm{rd}(\mathrm{x}, \mathrm{T} \mathrm{x})<\mathrm{d}(\mathrm{x}, \mathrm{y})$ implies that $\mathrm{H}(\mathrm{T} x, \mathrm{Ty})<\mathrm{d}(\mathrm{x}, \mathrm{y})$, then $\mathrm{F}(\mathrm{T})$ is nonempty.

On the other hand, concept of a metric has been generalized in many directions [14].

In 1993, Czerwik [8] introduced the notion of b-metric spaces as follows:

Definition 1.9. Let $X$ be a nonempty set and $b \geqslant 1$ a real number. A mapping $d: X \times X \rightarrow \mathbb{R}^{+}$is said to be a $b$-metric on $X$, if for any $x, y, z \in X$, the following conditions hold:

$\left(a_{1}\right) d(x, y)=0$, if and only if $x=y$;

$\left(a_{2}\right) d(x, y)=d(y, x)$;

$\left(a_{3}\right) d(x, y) \leqslant b(d(x, z)+d(z, y))$.

Every metric is $b$-metric for $b=1$, but converse does not hold in general [8, 24].

A number of results dealing with existence of fixed point of operators satisfying certain contractive conditions in the framework of $b$-metric spaces have been obtained $[2,7-10,15,17,18,24]$.

We now state the following lemmas from $[8-10,24]$ needed in the sequel.

Lemma 1.10. For any $b$-metric space $X, x, y \in X$ and $A, B \in C B(X)$, the following hold:

$\left.\mathrm{b}_{1}\right)$ If $(\mathrm{X}, \mathrm{d})$ is b-metric space, then so is $(\mathrm{CB}(\mathrm{X}), \mathrm{H})$.

$\left.b_{2}\right) d(x, B) \leqslant d(x, y)$ for all $y \in B$.

$\left.b_{3}\right) d(x, B) \leqslant H(A, B)$ for all $x \in A$.

$\left.b_{4}\right) d(x, A) \leqslant b(d(x, y)+d(y, A))$.

$\left.b_{5}\right)$ For $h>1$ and $a \in A$, there is $a b \in B$ such that $d(a, b) \leqslant h H(A, B)$.

$\left.\mathrm{b}_{6}\right)$ For $\mathrm{h}>0$ and $\mathrm{a} \in \mathrm{A}$, there is $a \mathrm{~b} \in \mathrm{B}$ such that $\mathrm{d}(\mathrm{a}, \mathrm{b}) \leqslant \mathrm{H}(\mathrm{A}, \mathrm{B})+\mathrm{h}$. 
$\left.b_{7}\right) d(x, A)=0$ if and only if $x \in \bar{A}=A$.

$\mathrm{b}_{8}$ ) For any sequence $\left\{\mathrm{u}_{\mathrm{n}}\right\}$ in $\mathrm{X}$,

$$
d\left(u_{0}, u_{n}\right) \leqslant b d\left(u_{0}, u_{1}\right)+\ldots+b^{n-1} d\left(u_{n-2}, u_{n-1}\right)+b^{n-1} d\left(u_{n-1}, u_{n}\right) .
$$

An et al. [2] studied some useful topological properties of b-metric spaces and showed that every $\mathrm{b}$-metric space is a semi-metrizable space. They also proved Stone-type theorem on b-metric spaces.

They stated [2, Example 3.9] the following useful facts about b-metric spaces.

$\left.c_{1}\right) d$ is not continuous in each variable.

$\mathrm{c}_{2}$ ) A b-metric is not necessarily a metric.

$c_{3}$ ) If $d$ is continuous in one variable then $d$ is continuous in other variable.

$c_{4}$ ) An open ball in b-metric space is not necessarily an open set. An open ball is open if $d$ is continuous in one variable.

Corollary $1.11([2,19])$. If $(\mathrm{X}, \mathrm{d})$ is a b-metric space and $\mathrm{A} \subset \mathrm{X}$. Then the following statements are equivalent.

$\left.c_{5}\right) x \in \bar{A}$.

$\left.\mathrm{c}_{6}\right)$ For every $\varepsilon>0, \mathrm{~B}(\mathrm{x}, \varepsilon) \cap \mathrm{A}$ is nonempty, where $\mathrm{B}(\mathrm{x}, \varepsilon)$ is an open ball centered at $\mathrm{x}$ with radius equal to $\varepsilon$.

$\left.c_{7}\right)$ There exists a sequence $\left\{x_{n}\right\}$ in A such that $\lim _{n \rightarrow \infty} x_{n}=x$.

Corollary $1.12([2,19])$. Let $(X, d)$ be a b-metric space and $A \subset X$. Then the following hold.

$\left.c_{8}\right) A$ is closed if and only if $x \in A$ for any sequence $\left\{x_{n}\right\} \subset A$ with $\lim _{n \rightarrow \infty} x_{n}=x$.

c9) For any $x \in \bar{A}$ and $\varepsilon>0, B(x, \varepsilon) \cap A$ is nonempty.

$\left.\mathrm{c}_{10}\right) \mathrm{A}$ is compact if and only if $\mathrm{A}$ is sequentially compact.

$\mathrm{C}_{11}$ ) If $\mathrm{A}$ is compact, then $\mathrm{A}$ is totally bounded.

Definition 1.13. Let $(X, d)$ be a b-metric space. The b-metric $d: X \times X \rightarrow \mathbb{R}^{+}$is continuous, if we have $\lim _{n \rightarrow \infty} d\left(x_{n}, y_{n}\right)=d(x, y)$ whenever $\left\{x_{n}\right\},\left\{y_{n}\right\}$ are sequences in $X$ such that $\lim _{n \rightarrow \infty} x_{n}=x$ and $\lim _{n \rightarrow \infty} y_{n}=y$.

Note that if b-metric function $d: X \times X \rightarrow \mathbb{R}^{+}$is continuous, then it is continuous in both the variables.

Throughout this paper, we assume the continuity of a b-metric $d: X \times X \rightarrow \mathbb{R}^{+}$.

\section{Main results}

In this section, we prove Edelstein-Suzuki variant of Hardy-Rogers type fixed point theorem for multivalued mappings in compact $b$-metric spaces.

Let $\Phi=\left\{\varphi: \mathbb{R}^{+} \times \mathbb{R}^{+} \rightarrow \mathbb{R}: \varphi(s, t) \leqslant \frac{1}{2 b} s-t\right\}$.

Theorem 2.1. Let $(\mathrm{X}, \mathrm{d})$ be a compact $\mathrm{b}$-metric space and $\mathrm{T}: \mathrm{X} \longrightarrow \mathrm{Cl}(\mathrm{X})$. If for any $\mathrm{x}, \mathrm{y} \in \mathrm{X}$

$$
\varphi(d(x, T x), d(x, y))<0,
$$

implies that

$$
H(T x, T y)<A d(x, y)+B d(x, T x)+C d(y, T y)+\frac{D}{b} d(x, T y)+E d(y, T x),
$$

where $\varphi \in \Phi, A, B, C, D, E \geqslant 0$ such that $A+B+C+2 D=\frac{1}{b}$ and $C \neq \frac{1}{b}$, then $\mathrm{T}$ has a fixed point. 
Proof. If $\beta=\inf _{x \in X} d(x, T x)$, then there exists a sequence $\left\{x_{n}\right\}$ in $X$ such that $\beta=\lim _{n \rightarrow \infty} d\left(x_{n}, T x_{n}\right)$. As $T x_{n}$ is closed in $(X, d)$ for each $n \in \mathbb{N}, T x_{n}$ is compact and hence for each $n \in \mathbb{N}$, there exists $y_{n} \in T x_{n}$ such that

$$
\beta=\lim _{n \rightarrow \infty} d\left(x_{n}, y_{n}\right) \text {. }
$$

Since $(X, d)$ is compact, it is sequentially compact $[2,19]$. Without loss of generality, we assume that $\left\{x_{n}\right\}$ and $\left\{y_{n}\right\}$ converge to $v$ and $w$, respectively. Thus we have

$$
\begin{gathered}
\beta=d(v, w)=\lim _{n} d\left(x_{n}, y_{n}\right), \\
\beta=\lim _{n} d\left(x_{n}, w\right)=d(v, w), \\
\beta=\lim _{n} d\left(v, y_{n}\right)=d(v, w), \\
\lim _{n} d\left(v, T x_{n}\right) \leqslant \lim _{n} d\left(v, y_{n}\right)=d(v, w)=\beta .
\end{gathered}
$$

Consequently,

$$
\lim _{n} d\left(v, T x_{n}\right) \leqslant \lim _{n} d\left(v, y_{n}\right)=\lim _{n} d\left(x_{n}, w\right)=\lim _{n} d\left(x_{n}, y_{n}\right)=\lim _{n} d\left(x_{n}, T x_{n}\right)=d(v, w)=\beta .
$$

We now claim that $\beta=0$. If $\beta>0$, then there exists an $n_{0} \in \mathbb{N}$ such that for all $n \geqslant n_{0}$, we have

$$
\frac{2 \beta}{3}<d\left(x_{n}, w\right)<\frac{4 \beta}{3} \text { and } \frac{2 \beta}{3}<d\left(x_{n}, T x_{n}\right)<\frac{4 \beta}{3} \text {. }
$$

Note that

$$
\varphi\left(d\left(x_{n}, T x_{n}\right), d\left(x_{n}, w\right)\right) \leqslant \frac{1}{2 b} d\left(x_{n}, T x_{n}\right)-d\left(x_{n}, w\right)<\frac{2 \beta}{3 b}-\frac{2 \beta}{3} \leqslant 0,
$$

for all $n \geqslant n_{0}$. Now by (2.1), we have

$$
\begin{aligned}
\frac{1}{b} d\left(y_{n}, T w\right) & \leqslant d\left(y_{n}, T w\right) \leqslant H\left(T x_{n}, T w\right) \\
& <\operatorname{Ad}\left(x_{n}, w\right)+B d\left(x_{n}, T x_{n}\right)+C d(w, T w)+\frac{D}{b} d\left(x_{n}, T w\right)+E d\left(w, T x_{n}\right) \\
& \leqslant A d\left(x_{n}, w\right)+B d\left(x_{n}, y_{n}\right)+C d(w, T w)+\frac{D}{b} d\left(x_{n}, T w\right)+E d\left(w, y_{n}\right),
\end{aligned}
$$

for all $n \geqslant n_{0}$. On taking limit as $n \rightarrow \infty$ on both sides of above inequality, we have

$$
\begin{aligned}
\frac{1}{b} d(w, T w) & \leqslant A d(v, w)+B d(v, w)+C d(w, T w)+\frac{D}{b} d(v, T w) \\
& \leqslant A d(v, w)+B d(v, w)+C d(w, T w)+D d(v, w)+D d(w, T w) \\
& \leqslant(A+B+D) d(v, w)+(C+D) d(w, T w)
\end{aligned}
$$

and hence

$$
\left(\frac{1}{b}-C-D\right) d(w, T w) \leqslant(A+B+D) d(v, w) .
$$

Obviously, $\frac{1}{b}-C-D \neq 0$. If $\frac{1}{b}-C-D=0$, then $A+B+C+2 D=\frac{1}{b}$ gives $A+B+D=\frac{1}{b}-C-D=0$ and hence $A=B=D=0$ and $C=\frac{1}{b}$, a contradiction. By (2.2), we obtain that $d(w, T w) \leqslant d(v, w)=\beta$. Hence, $\mathrm{d}(w, T w)=\beta$. Since $T w$ is nonempty and compact, for every minimizing sequence $\left\{w_{n}\right\} \in T w$, there exists a subsequence $\left\{w_{n_{k}}\right\}$ that converges to a point $w_{0}$ in Tw. That is, $w_{0}=\lim _{k \rightarrow \infty} w_{n_{k}}$. From $\lim _{k \rightarrow \infty} d\left(w, w_{n_{k}}\right)=\beta$, we have $d\left(w, w_{0}\right)=\beta$. If $w=w_{0}$, then $d\left(w, w_{0}\right)=\beta=0$, a contradiction to our supposition that $\beta>0$. Let $w \neq w_{0}$. Then, we have

$$
\varphi\left(d(w, T w), d\left(w, w_{0}\right)\right) \leqslant \frac{1}{2 b} d(w, T w)-d\left(w, w_{0}\right)
$$




$$
\begin{aligned}
& \leqslant \frac{1}{2 b} \mathrm{~d}\left(w, w_{0}\right)-\mathrm{d}\left(w, w_{0}\right) \\
& <\mathrm{d}\left(w, w_{0}\right)-\mathrm{d}\left(w, w_{0}\right)=0 .
\end{aligned}
$$

Thus

$$
\begin{aligned}
\frac{1}{b} d\left(w_{0}, T w_{0}\right) & \leqslant d\left(w_{0}, T w_{0}\right) \leqslant H\left(T w, T w_{0}\right) \\
& <\operatorname{Ad}\left(w, w_{0}\right)+\operatorname{Bd}(w, T w)+C d\left(w_{0}, T w_{0}\right)+\frac{D}{b} d\left(w, T w_{0}\right)+\operatorname{Ed}\left(w_{0}, T w\right) \\
& \leqslant A d\left(w, w_{0}\right)+B d\left(w, w_{0}\right)+C d\left(w_{0}, T w_{0}\right)+\frac{D}{b} d\left(w, T w_{0}\right)+\operatorname{Ed}\left(w_{0}, w_{0}\right) \\
& \leqslant A d\left(w, w_{0}\right)+B d\left(w, w_{0}\right)+C d\left(w_{0}, T w_{0}\right)+D d\left(w, w_{0}\right)+\operatorname{Dd}\left(w_{0}, T w_{0}\right) \\
& \leqslant(A+B+D) d\left(w, w_{0}\right)+(C+D) d\left(w_{0}, T w_{0}\right) .
\end{aligned}
$$

As $\frac{1}{b}-C-D \neq 0$,

$$
\left(\frac{1}{b}-C-D\right) d\left(w_{0}, T w_{0}\right)<(A+B+D) d\left(w, w_{0}\right),
$$

implies that $d\left(w_{0}, T w_{0}\right)<d\left(w, w_{0}\right)=\beta$, a contradiction to the definition of $\beta$. Hence $\beta=0$. We now prove that $T$ has a fixed point. If not, then $d\left(x_{n}, T x_{n}\right)>0$, for all $n \in \mathbb{N}$. Obviously, $\frac{1}{2 b} d\left(x_{n}, T x_{n}\right)<d\left(x_{n}, T x_{n}\right) \leqslant d\left(x_{n}, y_{n}\right)$. Note that

$$
\varphi\left(d\left(x_{n}, T x_{n}\right), d\left(x_{n}, y_{n}\right)\right) \leqslant \frac{1}{2 b} d\left(x_{n}, T x_{n}\right)-d\left(x_{n}, y_{n}\right)<0 .
$$

This further implies that

$$
\begin{aligned}
\frac{1}{b} d\left(y_{n}, T y_{n}\right) & \leqslant d\left(y_{n}, T y_{n}\right) \leqslant H\left(T x_{n}, T y_{n}\right) \\
& <A d\left(x_{n}, y_{n}\right)+B d\left(x_{n}, T x_{n}\right)+C d\left(y_{n}, T y_{n}\right)+\frac{D}{b} d\left(x_{n}, T y_{n}\right)+E d\left(y_{n}, T x_{n}\right) \\
& \leqslant A d\left(x_{n}, y_{n}\right)+B d\left(x_{n}, y_{n}\right)+C d\left(y_{n}, T y_{n}\right)+\frac{D}{b} d\left(x_{n}, T y_{n}\right) \\
& \leqslant A d\left(x_{n}, y_{n}\right)+B d\left(x_{n}, y_{n}\right)+C d\left(y_{n}, T y_{n}\right)+D d\left(x_{n}, y_{n}\right)+D d\left(y_{n}, T y_{n}\right),
\end{aligned}
$$

for all $n \in \mathbb{N}$. That is

$$
\left(\frac{1}{b}-C-D\right) d\left(y_{n}, T y_{n}\right)<(A+B+D) d\left(x_{n}, y_{n}\right)
$$

for all $n \in \mathbb{N}$. If $\frac{1}{b}-C-D=0$, then $A+B+D=\frac{1}{b}-C-D=0$, that is $A=B=D=0$ and hence $C=\frac{1}{b}$, a contradiction. Thus $\frac{1}{b}-C-D \neq 0$. Consequently

$$
d\left(y_{n}, T y_{n}\right)<d\left(x_{n}, y_{n}\right) .
$$

For each $n$, there exists $z_{n} \in T y_{n}$ such that $d\left(y_{n}, T y_{n}\right) \leqslant d\left(y_{n}, z_{n}\right)<d\left(y_{n}, T y_{n}\right)+\frac{1}{n}$. From (2.3), we have $\lim _{n} d\left(y_{n}, z_{n}\right)=\lim _{n} d\left(y_{n}, T y_{n}\right)=0$, which implies that $\lim _{n} d\left(v, z_{n}\right) \leqslant b\left(\lim _{n} d\left(v, y_{n}\right)+d\left(y_{n}, z_{n}\right)\right)=0$. Hence

$$
\lim _{n} d\left(v, z_{n}\right)=0 .
$$

Suppose that there exists some $n_{1} \in \mathbb{N}$ such that

$$
\varphi\left(d\left(x_{n_{1}}, T x_{n_{1}}\right), d\left(x_{n_{1}}, v\right)\right) \geqslant 0,
$$


and

$$
\varphi\left(d\left(y_{n_{1}}, T y_{n_{1}}\right), d\left(y_{n_{1}}, v\right)\right) \geqslant 0
$$

Then we have

$$
\frac{1}{2 b} d\left(x_{n_{1}}, T x_{n_{1}}\right) \geqslant d\left(x_{n_{1}}, v\right), \quad \text { and } \quad \frac{1}{2 b} d\left(y_{n_{1}}, T y_{n_{1}}\right) \geqslant d\left(y_{n_{1}}, v\right) \text {. }
$$

Using (2.3) and (2.4), we have

$$
\begin{aligned}
d\left(x_{n_{1}}, y_{n_{1}}\right) & \leqslant b\left(d\left(x_{n_{1}}, v\right)+d\left(y_{n_{1}}, v\right)\right) \\
& \leqslant \frac{1}{2} d\left(x_{n_{1}}, T x_{n_{1}}\right)+\frac{1}{2} d\left(y_{n_{1}}, T y_{n_{1}}\right) \\
& <\frac{1}{2} d\left(x_{n_{1}}, y_{n_{1}}\right)+\frac{1}{2} d\left(x_{n_{1}}, y_{n_{1}}\right)=d\left(x_{n_{1}}, y_{n_{1}}\right),
\end{aligned}
$$

a contradiction. Hence for all $n \in \mathbb{N}$, either $\varphi\left(d\left(x_{n}, T x_{n}\right), d\left(x_{n}, v\right)\right)<0$ or $\varphi\left(d\left(y_{n}, T y_{n}\right), d\left(y_{n}, v\right)\right)<0$. If $\varphi\left(d\left(x_{n}, T x_{n}\right), d\left(x_{n}, v\right)\right)<0$, then we have

$$
\begin{aligned}
\frac{1}{b} d\left(y_{n}, T v\right) & \leqslant d\left(y_{n}, T v\right) \leqslant H\left(T x_{n}, T v\right) \\
& <A d\left(x_{n}, w\right)+B d\left(x_{n}, T x_{n}\right)+C d(v, T v)+\frac{D}{b} d\left(x_{n}, T v\right)+E d\left(v, T x_{n}\right) .
\end{aligned}
$$

On taking limit as $n \rightarrow \infty$ we obtain that

$$
\frac{1}{b} d(v, T v) \leqslant\left(C+\frac{D}{b}\right) d(v, T v) \leqslant(C+D) d(v, T v)
$$

If $\varphi\left(d\left(y_{n}, T y_{n}\right), d\left(y_{n}, v\right)\right)<0$, then we have

$$
\begin{aligned}
\frac{1}{b} d\left(z_{n}, T v\right) & \leqslant d\left(z_{n}, T v\right) \leqslant H\left(T y_{n}, T v\right) \\
& <A d\left(y_{n}, v\right)+B d\left(y_{n}, T y_{n}\right)+C d(v, T v)+\frac{D}{b} d\left(y_{n}, T v\right)+E d\left(v, T y_{n}\right) .
\end{aligned}
$$

On taking limit as $n \rightarrow \infty$ we obtain that

$$
\frac{1}{b} d(v, T v) \leqslant\left(C+\frac{D}{b}\right) d(v, T v) \leqslant(C+D) d(v, T v)
$$

Thus we have $\frac{1}{b} d(v, T v) \leqslant(C+D) d(v, T v)$. Note that $C+D \neq \frac{1}{b}$. Otherwise, we have $A+B+D=0$, that is, $A=B=D=0$ and hence $C=\frac{1}{b}$, a contradiction. So $d(v, T v)=0$ and $v \in T v$, a contradiction to the assumption that $\mathrm{T}$ has no fixed point. Hence the result follows.

Remark 2.2. If in Theorem 2.1, $\varphi(s, t)=r s-t$ with $r \in\left[0, \frac{1}{2}\right)$ and $A=\frac{1}{b}, B=C=D=E=0$, then $\varphi \in \Phi$ and we obtain an extension of Theorem 1.8 to b-metric space.

Corollary 2.3. Let $(X, d)$ be a compact $\mathrm{b}$-metric space and $\mathrm{T}: \mathrm{X} \longrightarrow \mathrm{Cl}(\mathrm{X})$. If for any $\mathrm{x}, \mathrm{y} \in \mathrm{X}$, $\varphi(d(x, T x), d(x, y))<0$ implies $\mathrm{H}(T x, T y)<\frac{1}{b} d(x, y)$, where $\varphi \in \Phi$. Then Thas a fixed point in $X$.

Corollary 2.4. Let $(\mathrm{X}, \mathrm{d})$ be a compact $\mathrm{b}$-metric space and $\mathrm{f}: \mathrm{X} \longrightarrow \mathrm{X}$. If for any $\mathrm{x}, \mathrm{y} \in \mathrm{X}$,

$$
\varphi(d(x, f x), d(x, y))<0,
$$

implies that

$$
d(f x, f y)<A d(x, y)+B d(x, f x)+C d(y, f y)+\frac{D}{b} d(x, f y)+E d(y, f x),
$$

where $\varphi \in \Phi, A, B, C, D, E \geqslant 0$ such that $\mathrm{A}+\mathrm{B}+\mathrm{C}+2 \mathrm{D}=\frac{1}{\mathrm{~b}}$ and $\mathrm{C} \neq \frac{1}{\mathrm{~b}}$. Then $\mathrm{f}$ has a fixed point. Moreover $\mathrm{f}$ has a unique fixed point provided that $\mathrm{E}<\mathrm{B}+\mathrm{C}+\mathrm{D}$. 
Proof. Existence of fixed point of $f$ follows from Theorem 2.1. Let $v$ and $u$ be two fixed points of $f$ such that $v \neq u$. Then

$$
\varphi(d(v, f v), d(v, u)) \leqslant \frac{1}{2 b} d(v, f v)-d(v, u)=-d(v, u)<0 .
$$

Hence

$$
\begin{aligned}
\frac{1}{b} d(v, u) & \leqslant d(v, u)=d(f v, f u) \\
& <A d(v, u)+B d(v, f v)+C d(u, f u)+\frac{D}{b} d(v, f u)+E d(u, f v) \\
& \leqslant A d(v, u)+B d(v, v)+C d(u, u)+\frac{D}{b} d(v, u)+E d(u, v) \\
& \leqslant\left(A+\frac{D}{b}+E\right) d(v, u) \leqslant(A+D+E) d(v, u) .
\end{aligned}
$$

As $E<B+C+D$, so $A+D+E<A+B+C+2 D=\frac{1}{b}$ implies that $d(v, u)<d(v, u)$, a contradiction. Hence $f$ has a unique fixed point.

The above corollary generalizes and extends various comparable results in the existing literature.

Remark 2.5. If in Corollary 2.4, $\varphi(s, t)=\frac{1}{2 b} s-t$, then:

1. We obtain Theorem 1.3 in framework of b-metric space.

2. We have Theorem 1.2 in the setup of a $b$-metric space provided that $A=\frac{1}{b}$ and $B=C=D=E=0$.

3. We obtain Edelstein-Suzuki type version of Chatterjea fixed point result [6] in the setup of b-metric space provided that $A=B=0, D=\frac{1}{2}$.

Corollary 2.6. Let $(X, d)$ be a compact b-metric space and $f: X \longrightarrow X$. If for any $x, y \in X, \frac{1}{2 b} d(x, f x)<d(x, y)$ implies that $\mathrm{d}(\mathrm{fx}, \mathrm{fy})<\frac{1}{2 b} \mathrm{~d}(\mathrm{x}, \mathrm{fy})+\mathrm{Ed}(\mathrm{y}, \mathrm{fx})$, where $\mathrm{E} \geqslant 0$, then $\mathrm{f}$ has a fixed point in $\mathrm{X}$. Further, if $\mathrm{E} \leqslant \frac{1}{2}$, then $\mathrm{f}$ has a unique fixed point in $\mathrm{X}$.

Corollary 2.7. Let $(\mathrm{X}, \mathrm{d})$ be a compact $\mathrm{b}$-metric space and $\mathrm{f}: \mathrm{X} \longrightarrow \mathrm{X}$. If for any $\mathrm{x}, \mathrm{y} \in \mathrm{X}$,

$$
\varphi(d(x, f x), d(x, y))<0,
$$

implies that

$$
d(f x, f y)<B d(x, f x)+C d(y, f y),
$$

where $\varphi \in \Phi, \mathrm{B}, \mathrm{C} \geqslant 0$ such that $\mathrm{B}+\mathrm{C}=\frac{1}{\mathrm{~b}}$ and $\mathrm{C} \neq \frac{1}{\mathrm{~b}}$, then $\mathrm{f}$ has a unique fixed point in $\mathrm{X}$.

If in the above Corollary, $\varphi(s, t)=\frac{1}{2 b} s-t$, we obtain the following:

Corollary 2.8. Let $(X, d)$ be a compact $b$-metric space and $f: X \rightarrow X$. If for any $x, y \in X, \frac{1}{2 b} d(x, f x)<d(x, y)$ implies that $\mathrm{d}(\mathrm{fx}, \mathrm{fy})<\mathrm{Bd}(\mathrm{x}, \mathrm{fx})+\mathrm{Cd}(\mathrm{y}, \mathrm{fy})$ where $\mathrm{B}, \mathrm{C} \geqslant 0$ with $\mathrm{B}+\mathrm{C}=\frac{1}{\mathrm{~b}}$ and $\mathrm{C} \neq \frac{1}{\mathrm{~b}}$, then $\mathrm{f}$ has a unique fixed point in $\mathrm{X}$.

Corollary 2.9. Let $(X, d)$ be a compact $b$-metric space and $f: X \longrightarrow X$. If for any $x, y \in X, \varphi(d(x, f x), d(x, y))<0$ implies that $\mathrm{d}(\mathrm{fx}, \mathrm{fy})<\frac{1}{\mathrm{~b}} \mathrm{~d}(\mathrm{x}, \mathrm{y})$, where $\varphi \in \Phi$, then $\mathrm{f}$ has a unique fixed point in $\mathrm{X}$.

Example 2.10. Let $X=\left\{a_{1}, a_{2}, a_{3}\right\}$ and $d: X \times X \rightarrow \mathbb{R}^{+}$be defined as $d\left(a_{1}, a_{2}\right)=2, d\left(a_{2}, a_{3}\right)=\frac{1}{2}, d\left(a_{1}, a_{3}\right)=$ $1, d(x, y)=d(y, x)$ and $d(x, x)=0$ for all $x, y \in X$. Then $(X, d)$ is not a metric space, because $2=d(a, b) \not$ $d(a, c)+d(c, b)=\frac{3}{2}$. For $b=\frac{4}{3}, d$ is a b-metric. Let $\varphi(s, t)=\frac{1}{2 b} s-t$. Define $T: X \longrightarrow C l(X)$ as follows: 


$$
T x=\left\{\begin{array}{l}
\left\{a_{1}, a_{2}\right\}, \quad \text { when } x \neq a_{2} \\
\left\{a_{1}\right\}, \quad \text { when } x=a_{2}
\end{array}\right.
$$

Note that for all $x, y \in X$ such that $x \neq y$, we have $\frac{1}{2 b} d(x, T x)<d(x, y)$. Hence $\varphi(d(x, T x), d(x, y))<0$ for all $x, y \in X$ such that $x \neq y$. Further $H(T x, T y)=0$, for all $x, y \in\left\{a_{1}, a_{3}\right\}$ and $H\left(T a_{2}, T a_{3}\right)=H\left(T a_{2}, T a_{1}\right)=$ $H\left(\left\{a_{1}\right\},\left\{a_{1}, a_{3}\right\}\right)=1$. Let $A=\frac{1}{2}, B=\frac{1}{4}, C=D=0, E=\frac{1}{2}$, then $A+B+C+2 D=\frac{3}{4}=\frac{1}{b}$. Hence

$$
\begin{aligned}
& H\left(T a_{2}, T a_{3}\right)=1<\operatorname{Ad}\left(a_{2}, a_{3}\right)+\operatorname{Bd}\left(a_{2}, T a_{2}\right)+\operatorname{Ed}\left(a_{3}, T a_{2}\right)=\frac{5}{4}, \\
& H\left(T a_{2}, T a_{1}\right)=1<\operatorname{Ad}\left(a_{2}, a_{1}\right)+\operatorname{Bd}\left(a_{2}, T a_{2}\right)+\operatorname{Ed}\left(a_{1}, T a_{2}\right)=\frac{3}{2} .
\end{aligned}
$$

Therefore $\varphi(d(x, T x), d(x, y))<0$ implies that

$$
H(T x, T y)<A d(x, y)+B d(x, T x)+C d(y, T y)+\frac{D}{b} d(x, T y)+E d(y, T x),
$$

holds for all $x, y \in X, A, B, C, D, E \geqslant 0$ such that $A+B+C+2 D=\frac{1}{b}$ and $\varphi \in \Phi$. So all the conditions of Theorem 2.1 are satisfied. Here, $a_{1}$ and $a_{2}$ are fixed points of $T$.

Remark 2.11. Consider the b-metric $d$ on $X=\left\{a_{1}, a_{2}, a_{3}\right\}$ and mapping $T$ same as in Example 2.10. Let $x=a_{2}, y=a_{3}$, then $H\left(T a_{2}, T a_{3}\right)=1 \nless \frac{3}{8}=\frac{1}{b} d\left(a_{2}, a_{3}\right)$ and hence Corollary 2.3 is not applicable in this case. Note that Corollary 2.3 is generalization of Theorem 1.1 and Theorem 1.2 for multivalued mappings in the context of $b$-metric space.

\section{Edelstein-Suzuki type coincidence and common fixed point result for a hybrid pair of mappings}

Let $(X, d)$ be a b-metric space, $g: X \rightarrow X$ and $T: X \rightarrow \operatorname{Cl}(X)$. A point $X$ in $X$ is called

(i) a coincidence point of hybrid pair $(g, T)$, if $g x \in T x$;

(ii) a common fixed point of hybrid pair $(g, T)$, if $x=g x \in T x$.

Denote $C(g, T)$ and $F(g, T)$ by the set of all coincidence and common fixed points of hybrid pair $(g, T)$. In consistent with $[1,13]$, we need the following definitions and result in the sequel.

Definition 3.1. A hybrid pair $(g, T)$ is called $w$-compatible, if $g(T x) \subseteq T(g x)$, for all $x \in C(g, T)$.

The mapping $g$ is called T-weakly commuting at some point $x \in X$, if $g^{2}(x) \in T(g x)$.

Haghi et al. [13] proved the following lemma by using axiom of choice.

Lemma 3.2 ([13]). Let $X$ be a nonempty set and $g: X \rightarrow X$. Then there exists a subset $E \subseteq X$ such that $g(E)=g(X)$ and $\mathrm{g}: \mathrm{E} \rightarrow \mathrm{X}$ is one-to-one.

We now prove the following result.

Theorem 3.3. Let $(\mathrm{X}, \mathrm{d})$ be a $\mathrm{b}$-metric space and $(\mathrm{g}, \mathrm{T})$ a hybrid pair of mappings. If for any $\mathrm{x}, \mathrm{y} \in \mathrm{X}$

$$
\varphi(d(g x, T x), d(g x, g y))<0,
$$

implies that

$$
H(T x, T y)<A d(g x, g y)+B d(g x, T x)+C d(g y, T y)+\frac{D}{b} d(g x, T y)+E d(g y, T x),
$$

where $\varphi \in \Phi, A, B, C, D, E \geqslant 0$ with $\mathrm{A}+\mathrm{B}+\mathrm{C}+2 \mathrm{D}=\frac{1}{\mathrm{~b}}$ and $\mathrm{C} \neq \frac{1}{\mathrm{~b}}$, then $\mathrm{C}(\mathrm{g}, \mathrm{T})$ is nonempty provided that $\mathrm{T}(X) \subseteq \mathrm{g}(X)$ and $\mathrm{g}(X)$ is compact. Further $\mathrm{F}(\mathrm{g}, \mathrm{T})$ is nonempty if any of the following conditions hold: 
$\mathrm{d}_{1}$ - The hybrid pair $(\mathrm{g}, \mathrm{T})$ is $\mathrm{w}$-compatible, $\lim _{\mathrm{n} \rightarrow \infty} \mathrm{g}^{\mathrm{n}}(\mathrm{x})=\mathrm{u}$, for some $\mathrm{u} \in \mathrm{X}, \mathrm{x} \in \mathrm{C}(\mathrm{g}, \mathrm{T})$ and $\mathrm{g}$ is continuous at $\mathrm{u}$.

$\mathrm{d}_{2}$ - The mapping $\mathrm{g}$ is $\mathrm{T}$-weakly commuting at some $\mathrm{x} \in \mathrm{C}(\mathrm{g}, \mathrm{T})$ and $\mathrm{g}^{2} \mathrm{x}=\mathrm{gx}$.

$\mathrm{d}_{3^{-}}$The mapping $\mathrm{g}$ is continuous at some $\mathrm{x} \in \mathrm{C}(\mathrm{g}, \mathrm{T})$ and $\lim _{\mathrm{n} \rightarrow \infty} \mathrm{g}^{\mathrm{n}}(\mathrm{u})=x$, for some $\mathrm{u} \in \mathrm{X}$.

Proof. By Lemma 3.2, there is a set $E \subseteq X$ such that $g: E \rightarrow X$ is one-to-one and $g(E)=g(X)$. Then a mapping $\mathcal{T}: g(E) \rightarrow \mathrm{Cl}(X)$ defined as $\mathcal{T}(g x)=T(x)$ for all $g(x) \in g(E)$ is well-defined because $g$ is one-to-one. Also

$$
\left\{\begin{array}{l}
\varphi(d(g x, T x), d(g x, g y))<0, \quad \text { implies that } \\
H(T x, T y)<A d(g x, g y)+B d(g x, T x)+C d(g y, T y)+\frac{D}{b} d(g x, T y)+E d(g y, T x) .
\end{array}\right.
$$

Thus

$$
\left\{\begin{array}{l}
\varphi(\mathrm{d}(\mathrm{gx}, \mathcal{T}(\mathrm{gx})), \mathrm{d}(\mathrm{gx}, \mathrm{gy}))<0, \quad \text { implies that } \\
\mathrm{H}(\mathcal{T}(\mathrm{gx}), \mathcal{T}(\mathrm{gy}))<\mathrm{Ad}(\mathrm{gx}, \mathrm{gy})+\mathrm{Bd}(\mathrm{gx}, \mathcal{T}(\mathrm{gx}))+\mathrm{Cd}(\mathrm{gy}, \mathcal{T}(\text { gy })) \\
\quad+\frac{\mathrm{D}}{\mathrm{b}} \mathrm{d}(\mathrm{gx}, \mathcal{T}(\text { gy }))+\mathrm{Ed}(\text { gy }, \mathcal{T}(g x)),
\end{array}\right.
$$

for all $g x, g y \in g(E)$. As $g(E)=g(X)$ is compact, $\mathcal{T}$ satisfies all the conditions of Theorem 2.1 with mapping $\mathcal{T}$ on $g(E)$. There exists a point $u \in g(E)$ such that $u \in \mathcal{T} u$. Since $T(X) \subseteq g(X)$, there is a point $x$ in $X$ such that $g x=u$. This implies that $g x \in \mathcal{T} g x=T x$. That is $x \in C(g, T)$. Now we prove that $F(g, T)$ is nonempty. Let $\left(C_{1}\right)$ hold. As the pair $(g, T)$ is $w$-compatible and $\lim _{n \rightarrow \infty} g^{n}(x)=u$ for some $u \in X$, the continuity of $g$ at $u$ implies that $g u=u$ and the $w$-compatibility of the pair $(g, T)$ implies that $g^{n}(x) \in T\left(g^{n-1}(x)\right)$, that is $g^{n}(x) \in C(g, T)$ for all $n \in \mathbb{N}$. Note that $g^{n}(x) \neq g(u)$ for all $n$, if $g^{n}(x)=g(u)$ for some $n$, then we have $u=g u=g^{n}(x) \in T\left(g^{n-1}(x)\right)=T(u)$ and the proof is done. So let $g^{n}(x) \neq g(u)$ for all $n$, we further get

$$
\begin{aligned}
\varphi\left(d\left(g^{n}(x), T\left(g^{n-1}(x)\right)\right), d\left(g g^{n-1}(x), g u\right)\right) & \leqslant \frac{1}{2 b} d\left(g^{n}(x), T\left(g^{n-1}(x)\right)\right)-d\left(g g^{n-1}(x), g u\right) \\
& =0-d\left(g g^{n-1}(x), g u\right)<0 .
\end{aligned}
$$

This implies that

$$
\begin{aligned}
\frac{1}{b} d\left(g^{n}(x), T u\right) \leqslant & d\left(g^{n}(x), T u\right) \leqslant H\left(T\left(g^{n-1}(x)\right), T u\right) \\
< & A d\left(g^{n}(x), g u\right)+B d\left(g^{n}(x), T\left(g^{n-1}(x)\right)\right) \\
& +C d(g u, T u)+\frac{D}{b} d\left(g^{n}(x), T u\right)+E d\left(g u, T\left(g^{n-1}(x)\right)\right) \\
\leqslant & A d\left(g^{n}(x), g u\right)+B d\left(g^{n}(x), g^{n}(x)\right) \\
& +C d(g u, T u)+\frac{D}{b} d\left(g^{n}(x), T u\right)+E d\left(g u, g^{n}(x)\right) .
\end{aligned}
$$

On taking limit as $n \rightarrow \infty$, we obtain $\frac{1}{b} d(g u, T u) \leqslant C d(g u, T u)+\frac{D}{b} d(g u, T u) \leqslant(C+D) d(g u, T u)$. That is, $\left(\frac{1}{b}-C-D\right) d(g u, T u) \leqslant d(g u, T u)$. If $\frac{1}{b}-C-D=0$, then $A+B+D=0$, consequently $A=B=D=0$, that is $C=\frac{1}{b}$, a contradiction, hence $d(g u, T u)=0$ implies that $u=g u \in T u$. To prove $F(g, T)$ is nonempty, let $\left(C_{2}\right)$ hold. Thus for some $x \in C(g, T), g^{2} x=g x$. Since $g$ is T-weakly commuting, therefore $g x=g^{2} x \in T(g x)$. Hence $g x \in F(g, T)$. If $\left(C_{3}\right)$ holds, then $\lim _{n \rightarrow \infty} g^{n}(u)=x$ for some $u \in X$ and $x \in C(g, T)$. Using continuity of $g$ we get $x=g x \in T x$. Hence $F(g, T)$ is nonempty.

Corollary 3.4. Let $(\mathrm{X}, \mathrm{d})$ be a $\mathrm{b}$-metric space and $(\mathrm{g}, \mathrm{T})$ be a hybrid pairs of mappings satisfying $\mathrm{T}: \mathrm{X} \longrightarrow \mathrm{Cl}(\mathrm{X})$ be a multivalued mapping satisfying $\frac{1}{2 \mathrm{~b}} \mathrm{~d}(\mathrm{gx}, \mathrm{Tx})<\mathrm{d}(\mathrm{gx}, \mathrm{gy})$ implies that $\mathrm{H}(\mathrm{Tx}, \mathrm{Ty})<\mathrm{d}(\mathrm{gx}, \mathrm{gy})$ for all $\mathrm{x}, \mathrm{y} \in \mathrm{X}$. Then $\mathrm{C}(\mathrm{g}, \mathrm{T})$ is nonempty provided that $\mathrm{T}(\mathrm{X}) \subseteq \mathrm{g}(\mathrm{X})$ and $\mathrm{g}(\mathrm{X})$ is compact. Further $\mathrm{F}(\mathrm{g}, \mathrm{T})$ is nonempty if $\left(\mathrm{d}_{1}\right)-\left(\mathrm{d}_{3}\right)$ hold as given in Theorem 3.3. 


\section{Fixed point theorems in metric spaces with application in best approximation theory}

If we take $b=1$ in Theorem 2.1, we get the following result in metric spaces.

Theorem 4.1. Let $(\mathrm{X}, \mathrm{d})$ be a compact metric space and $\mathrm{T}: \mathrm{X} \longrightarrow \mathrm{Cl}(\mathrm{X})$. If for any $\mathrm{x}, \mathrm{y} \in \mathrm{X}$

$$
\varphi(d(x, T x), d(x, y))<0,
$$

implies that $\mathrm{H}(\mathrm{T} x, \mathrm{Ty})<\mathrm{Ad}(x, y)+\mathrm{Bd}(x, \mathrm{~T} x)+\mathrm{Cd}(\mathrm{y}, \mathrm{Ty})+\mathrm{Dd}(x, \mathrm{Ty})+\mathrm{Ed}(\mathrm{y}, \mathrm{T} x)$, where $\varphi \in \Phi, A, B, C$, $\mathrm{D}, \mathrm{E} \geqslant 0$ such that $\mathrm{A}+\mathrm{B}+\mathrm{C}+2 \mathrm{D}=1$ and $\mathrm{C} \neq 1$. Then $\mathrm{T}$ has a fixed point.

Corollary 4.2. Let $(X, d)$ be a compact metric space and $f: X \longrightarrow X$. If for any $x, y \in X$,

$$
\varphi(d(x, f x), d(x, y))<0,
$$

implies that

$$
d(f x, f y)<A d(x, y)+B d(x, f x)+C d(y, f y)+D d(x, f y)+E d(y, f x),
$$

where, $\varphi \in \Phi, A, B, C, D, E \geqslant 0$ such that $\mathrm{A}+\mathrm{B}+\mathrm{C}+2 \mathrm{D}=1$ and $\mathrm{C} \neq 1$. Then $\mathrm{f}$ has a fixed point. Moreover $\mathrm{f}$ has a unique fixed point provided that $\mathrm{E} \leqslant \mathrm{B}+\mathrm{C}+\mathrm{D}$.

Corollary 4.3. Let $(X, d)$ be a compact metric space and $\mathrm{f}: \mathrm{X} \longrightarrow \mathrm{X}$ be a mapping satisfying $\frac{1}{2} \mathrm{~d}(\mathrm{y}, \mathrm{fx})<\mathrm{d}(\mathrm{X}, \mathrm{y})$ implies that $\mathrm{d}(\mathrm{f} x, \mathrm{fy})<\mathrm{d}(\mathrm{x}, \mathrm{y})$ for all $\mathrm{x}, \mathrm{y} \in \mathrm{X}$. Then $\mathrm{f}$ has a unique fixed point in $\mathrm{X}$.

Corollary 4.4. Theorem 1.1.

Example 4.5. Let $X=\{a, b, c\}$ and $d: X \times X \rightarrow \mathbb{R}^{+}$be defined as

$$
\begin{aligned}
& d(a, b)=4=d(b, c), d(a, c)=2, \\
& d(x, y)=d(y, x), \quad \text { and } \quad d(x, x)=0, \quad \forall x, y \in X .
\end{aligned}
$$

Then $(X, d)$ is a metric space. Let $\varphi(s, t)=\frac{1}{2} s-t$. Define $f: X \longrightarrow \operatorname{Cl}(X)$ as follows:

$$
f x= \begin{cases}b, & \text { when } x \neq c, \\ c, & \text { when } x=c .\end{cases}
$$

For $x=a, y=c, \frac{1}{2} d(a, f a)=\frac{1}{2} d(a, b)=2=d(a, c)$. Note that $\frac{1}{2} d(x, f x)-d(x, y)<0$ holds for all $x, y \in X$ and $x \neq a$ and $y \neq c$. Further $d(f a, f c)=d(f b, f c)=d(b, c)=4, d(f a, f b)=d(b, b)=0$. Let $\mathrm{A}=\mathrm{B}=\frac{1}{4}, \mathrm{E}=\frac{2}{3}, \mathrm{D}=\frac{1}{4}$ and $\mathrm{C}=0$. Then $\mathrm{A}+\mathrm{B}+\mathrm{C}+2 \mathrm{D}=1$. Hence

$$
\begin{aligned}
d(f a, f c) & =4<A d(a, c)+B d(a, f a)+C d(c, f c)+D d(a, f c)+E d(c, f a) \\
& =A d(a, c)+B d(a, b)+C d(c, c)+D d(a, c)+E d(c, b) \\
& =2 A+4 B+2 D+4 E=\frac{14}{3} \\
d(f b, f c) & =4<A d(b, c)+B d(b, f b)+C d(c, f c)+D d(b, f c)+E d(c, f b) \\
& =A d(b, c)+B d(b, b)+C d(c, c)+D d(b, c)+E d(c, b) \\
& =4 A+4 D+4 E=\frac{14}{3} .
\end{aligned}
$$

Therefore

$$
\varphi(d(x, f x), d(x, y))<0
$$

implies

$$
d(f x, f y)<A d(x, y)+B d(x, f x)+C d(y, f y)+D d(x, f y)+E d(y, f x),
$$

for all $x, y \in X$ such that $A, B, C, D, E \geqslant 0$ and $A+B+C+2 D=1$. So all the conditions of Corollary 4.2 are satisfied. Here, $b$ and $c$ are fixed points of $f$. 
Remark 4.6. Consider the metric $d$ on $X=\{a, b, c\}$ and mapping $f$ same as in Example 2.10.

- If $x=b, y=c$, then $d(f b, f c)=d(b, c)=4$ and hence Theorem 1.1 is not applicable in this case.

- If $x=b, y=c$, then $\frac{1}{2} d(b, f b)=0<4=d(b, c)$ holds but $d(f b, f c)=d(b, c)=4$. Hence Theorem 1.2 is not applicable in this case.

- If $x=b, y=c$, then we have $r d(b, f b)+s d(c, f b)=r d(b, b)+s d(c, b)<d(c, b)$ for any $s<1$ and $2 r+s<1$. As $d(f b, f c)=d(b, c)=4$ and $d(b, c)=4, d(b, f b)=0, d(c, f c)=0, \frac{d(b, f c)}{2}=\frac{d(c, f b)}{2}=$ 2. Hence

$$
4=d(f b, f c) \nless 4=\max \left\{d(b, c), d(b, f b), d(c, f c), \frac{d(b, f c)}{2}, \frac{d(c, f b)}{2}\right\} .
$$

Thus Theorem 1.4 and Theorem 1.5 are not applicable in this case.

- If $x=b, y=c$, then $d(b, c)=4, d(b, f b)=0, d(c, f c)=0, \frac{1}{2}(d(b, f c)+d(c, f b))=4$. Hence

$$
4=d(f b, f c) \nless 4 r=r \max \left\{d(b, c), d(b, f b), d(c, f c), \frac{d(b, f c)+d(c, f b)}{2}\right\},
$$

for any $r \in\left[0, \frac{1}{2}\right)$. So Theorem 1.7 is not applicable in this case.

- If $x=b, y=c$, then $r d(b, f b)<d(c, b)$ holds for any $r \in\left(0, \frac{1}{2}\right]$ but $d(f b, f c)=d(b, c)=4$ implies that Theorem 1.8 is not applicable in this case.

\subsection{Application in best approximation}

Let $(X,\|\cdot\|)$ be a normed linear space. A mapping $f: X \rightarrow X$ is called nonexpansive on $X$, if $\|f x-f y\| \leqslant$ $\|x-y\|$ for all $x, y \in X$. A subset $C$ of $X$ is said to be $f$-invariant, if $f(C) \subseteq C$. The set $F(f)=\{x \in X: x=f x\}$ is a fixed point set of $f$ and the set

$$
P_{C}(\tilde{x})=\left\{y \in C \subseteq X:\|y-\tilde{x}\|=\inf _{z \in C}\|z-\tilde{x}\|\right\},
$$

is a set of best $C$-approximations of $\tilde{x}$. A subset $C$ of $X$ is called a starshaped with respect to $q \in C$, if for all $x$ in $C$ and $\lambda \in[0,1], \lambda x+(1-\lambda) q \in C$. Note that a convex set $C$ is starshaped with respect to every $q$ in C. Brosowski [5] proved the following theorem in approximation theory.

Theorem 4.7 ([5]). Let $\mathrm{f}$ be a linear, nonexpansive mapping on a normed linear space $\mathrm{X}$ and $\mathrm{C}$ an $\mathrm{f}$-invariant subset of $\mathrm{X}$ and $\mathrm{x} \in \mathrm{F}(\mathrm{f})$. If $\mathrm{P}_{\mathrm{C}}(\mathrm{X})$ is nonempty, compact and convex then $\mathrm{P}_{\mathrm{C}}(\mathrm{x}) \cap \mathrm{F}(\mathrm{f})$ is nonempty.

Singh [23] improved the Brosowski theorem by relaxing the linearity of the mapping $f$ and the convexity of the subset $C$.

Theorem 4.8 ([23]). Let $\mathrm{f}$ be a nonexpansive mapping on a normed linear space $\mathrm{X}$ and $\mathrm{C}$ an $\mathrm{f}$-invariant subset of $\mathrm{X}$ and $\mathrm{x} \in \mathrm{F}(\mathrm{f})$. If $\mathrm{P}_{\mathrm{C}}(\mathrm{x})$ is nonempty, compact and starshaped then $\mathrm{P}_{\mathrm{C}}(\mathrm{x}) \cap \mathrm{F}(\mathrm{f})$ is nonempty.

Suzuki [26] introduced the concept of generalized nonexpansive mappings on a normed linear space. Let $f$ be a mapping on a normed linear space $X$ that satisfies

$$
\frac{1}{2}\|x-f x\| \leqslant\|x-y\|, \quad \text { implies that }\|f x-f y\| \leqslant\|x-y\|,
$$

for all $x, y \in X$. This condition on mappings is known as condition $(C)$ which is weaker than nonexpansiveness but stronger than quasi-nonexpansiveness.

Now we prove the following theorem for generalized nonexpansive mappings (that satisfy condition (C)) on a normed linear spaces. 
Theorem 4.9. Let $\mathrm{f}$ be a mapping on a normed linear space $\mathrm{X}$ that satisfies condition $(\mathrm{C})$ for all $\mathrm{x}, \mathrm{y} \in \mathrm{X}$ and $\mathrm{C}$ an $f$-invariant subset of $X$ and $\tilde{x} \in F(f)$. If $P_{C}(\tilde{x})$ is nonempty, compact and starshaped then $\mathrm{P}_{C}(\tilde{x}) \cap F(f)$ is nonempty provided that $\|\mathrm{y}-\mathrm{fx}\| \leqslant\|x-\mathrm{y}\|$ holds for all $\mathrm{x}, \mathrm{y} \in \mathrm{P}_{\mathrm{C}}(\tilde{\mathrm{x}})$.

Proof. Consider $f: \mathrm{P}_{\mathrm{C}}(\tilde{x}) \rightarrow \mathrm{P}_{\mathrm{C}}(\tilde{x})$. Let $\mathrm{y} \in \mathrm{P}_{\mathrm{C}}(\tilde{\mathrm{x}})$. Then, we have

$$
\frac{1}{2}\|\tilde{x}-f \tilde{x}\|=\frac{1}{2}\|\tilde{x}-\tilde{x}\|=0 \leqslant\|\tilde{x}-y\|,
$$

for all $y \in P_{C}(\tilde{x})$. This implies that $\|f y-\tilde{x}\|=\|f y-f \tilde{x}\| \leqslant\|\tilde{x}-y\|$. Consequently $f y \in P_{C}(\tilde{x})$, that is $f$ is $\mathrm{P}_{\mathrm{C}}(\tilde{\mathrm{x}})$-invariant. Fix $\mathrm{p} \in \mathrm{P}_{\mathrm{C}}(\tilde{\mathrm{x}})$ such that

$$
\lambda p+(1-\lambda) x \in P_{C}(\tilde{x}),
$$

for all $x \in P_{C}(\tilde{x})$ and $\lambda \in[0,1]$. Let $\left\{k_{n}\right\} \in[0,1)$ such that $\lim _{n \rightarrow \infty} k_{n}=1$. Define $f_{n}: P_{C}(\tilde{x}) \rightarrow P_{C}(\tilde{x})$ as $f_{n} x=k_{n} f x+\left(1-k_{n}\right) p$ for all $x \in P_{C}(\tilde{x})$. Since $f$ is $P_{C}(\tilde{x})$-invariant, therefore by $(4.2) f_{n}$ is $P_{C}(\tilde{x})$-invariant. Moreover we have

$$
\frac{1}{2}\|x-f x\| \leqslant \frac{1}{2}\|x-y\|+\frac{1}{2}\|y-f x\| \leqslant \frac{1}{2}\|x-y\|+\frac{1}{2}\|x-y\|=\|x-y\|,
$$

for all $x, y \in P_{C}(\tilde{x})$. By (4.1) we obtain

$$
\left\|f_{n} x-f_{n} y\right\|=k_{n}\|f x-f y\| \leqslant k_{n}\|x-y\|<\|x-y\|,
$$

for all $x, y \in P_{C}(\tilde{x})$ and for all $n \in \mathbb{N}$. Since $P_{C}(\tilde{x})$ is compact, therefore by Corollary 4.4 , for all $n \in \mathbb{N}$, $f_{n}$ has a unique fixed point, say $x_{n}$. Thus $f_{n} x_{n}=x_{n}$ for all $n \in \mathbb{N}$. The compactness of $P_{C}(\tilde{x})$ yields a convergent subsequence $x_{n_{i}}$ converging to $\bar{x} \in P_{C}(\tilde{x})$ (say). Hence $x_{n_{i}}=f_{n_{i}} x_{n_{i}}=k_{n_{i}} f x_{n_{i}}+\left(1-k_{n_{i}}\right) p$. On taking limit as $i \rightarrow \infty$, we obtain $\bar{x}=f \bar{x}$.

\section{Acknowledgment}

The authors extend their appreciation to the International partnership program (ISSP) at King Saud University for funding this research work through ISSP\#0034. We are sincerely grateful to the editor and referees for their careful reading, thoughtful suggestions and critical remarks for improving the quality of this manuscript.

\section{References}

[1] M. Abbas, L. Ćirić, B. Damjanović, M. A. Khan, Coupled coincidence and common fixed point theorems for hybrid pair of mappings, Fixed Point Theory Appl., 2012 (2012), 11 pages. 3

[2] T. V. An, L. Q. Tuyen, N. V. Dung, Stone-type theorem on b-metric spaces and applications, Topology Appl., 185/186 (2015), 50-64. 1, 1, 1.11, 1.12, 2

[3] S. Banach, Sur les opérations dans les ensembles abstraits et leur application aux équations intégrales, Fund. Math., 3 (1922), 133-181. 1

[4] I. Beg, S. M. A. Aleomraninejad, Fixed points of Suzuki type multifunctions on metric spaces, Rend. Circ. Mat. Palermo, 64 (2015), 203-207. 1, 1.8

[5] B. Brosowski, Fixpunktsätze in der Approximationstheorie, (German) Mathematica (Cluj), 11 (1969), 195-220. 4.1, 4.7

[6] S. K. Chatterjea, Fixed-point theorems, C. R. Acad. Bulgare Sci., 25 (1972), 727-730. 1, 3

[7] C. Chifu, G. Petruşel, Fixed points for multivalued contractions in b-metric spaces with applications to fractals, Taiwanese J. Math., 18 (2014), 1365-1375. 1

[8] S. Czerwik, Contraction mappings in b-metric spaces, Acta Math. Inform. Univ. Ostraviensis, 1 (1993), 5-11. 1, 1, 1

[9] S. Czerwik, Nonlinear set-valued contraction mappings in b-metric spaces, Atti Sem. Mat. Fis. Univ. Modena, 46 (1998), 263-276.

[10] S. Czerwik, K. Dlutek, S. L. Singh, Round-off stability of iteration procedures for operators in b-metric spaces, J. Natur. Phys. Sci., 11 (1997), 87-94. 1 
[11] D. Dorić, Z. Kadelburg, S. Radenović, Edelstein-Suzuki-type fixed point results in metric and abstract metric spaces, Nonlinear Anal., 75 (2012), 1927-1932. 1, 1.3

[12] M. Edelstein, On fixed and periodic points under contractive mappings, J. London Math. Soc., 37 (1962), 74-79. 1, 1.1

[13] R. H. Haghi, S. Rezapour, N. Shahzad, Some fixed point generalizations are not real generalizations, Nonlinear Anal., 74 (2011), 1799-1803. 3, 3, 3.2

[14] L.-G. Huang, X. Zhang, Cone metric spaces and fixed point theorems of contractive mappings, J. Math. Anal. Appl., 332 (2007), 1468-1476. 1

[15] N. Hussain, D. Dorić, Z. Kadelburg, S. Radenović, Suzuki-type fixed point results in metric type spaces, Fixed Point Theory Appl., 2012 (2012), 12 pages. 1

[16] R. Kannan, Some results on fixed points, II, Amer. Math. Monthly, 76 (1969), 405-408. 1

[17] E. Karapinar, Edelstein type fixed point theorems, Ann. Funct. Anal., 2 (2011), 51-58. 1, 1.5, 1

[18] E. Karapinar, Edelstein type fixed point theorems, Fixed Point Theory Appl., 2012 (2012), 12 pages. 1, 1

[19] M. A. Khamsi, N. Hussain, KKM mappings in metric type spaces, Nonlinear Anal., 73 (2010), 3123-3129. 1.11, 1.12, 2

[20] S. B. Nadler Jr., Multi-valued contraction mappings, Pacific J. Math., 30 (1969), 475-488. 1, 1.6

[21] O. Popescu, Some generalizations of Suzuki and Edelstein type theorems, Fixed Point Theory Appl., 2013 (2013), 11 pages. $1,1.4$

[22] F. Shaddad, M. Salmi, S. M. Alsulami, Common fixed point results of Ciric-Suzuki-type inequality for multivalued maps in compact metric spaces, J. Inequal. Appl., 2014 (2014), 11 pages. 1, 1.7

[23] S. P. Singh, An application of a fixed-point theorem to approximation theory, J. Approx. Theory, 25 (1979), 89-90. 4.1, 4.8

[24] S. L. Singh, B. Prasad, Some coincidence theorems and stability of iterative procedures, Comput. Math. Appl., 55 (2008), 2512-2520. 1

[25] T. Suzuki, A generalized Banach contraction principle that characterizes metric completeness, Proc. Amer. Math. Soc., 136 (2008), 1861-1869. 1

[26] T. Suzuki, Fixed point theorems and convergence theorems for some generalized nonexpansive mappings, J. Math. Anal. Appl., 340 (2008), 1088-1095. 4.1

[27] T. Suzuki, A new type of fixed point theorem in metric spaces, Nonlinear Anal., 71 (2009), 5313-5317. 1, 1

[28] E. Tarafdar, An approach to fixed-point theorems on uniform spaces, Trans. Amer. Math. Soc., 191 (1974), $209-225.1$ 